\title{
Review
}

\section{Repair of spinal cord injury: ripples of an incoming tide, or how I spent my first 40 years in research}

\author{
G Raisman ${ }^{1, *}$ \\ ${ }^{1}$ Spinal Repair Unit, Institute of Neurology, University College London, London, UK
}

\begin{abstract}
Chair of Neural Regeneration at University College London January 2006. Record of personal research. Electron microscopic observations led to the concept that the adult brain is capable of forming new synapses after injury, and the search for methods to repair brain and spinal cord injuries. It is proposed that the failure of regeneration after central axotomy is due to protective glial scarring leading to the loss of the aligned astrocytic pathways needed for axon elongation. Taking advantage of the discovery that the adult olfactory system is capable of continual renewal, cultured olfactory ensheathing cells were transplanted into lesions of the spinal cord and spinal roots. The transplants re-opened scarred glial pathways, allowed the regeneration of severed nerve fibres, and the restoration of various functions, including paw reaching, climbing, and supraspinal respiratory impulses to the phrenic nerve.

Spinal Cord (2006) 44, 406-413. doi:10.1038/sj.sc.3101948; published online 6 June 2006
\end{abstract}

Keywords: olfactory ensheathing cell; transplants; repair; pathway hypothesis; astrocytes; recovery of function

There is no such thing as an inauguration. Everything is an effect of some cause before it. And every cause is an effect of an earlier cause. My father wanted me to be a doctor. I only just failed to fulfil his wish. But in the end I did not become a doctor. My father was a tailor. $\mathrm{He}$ himself was the son of an immigrant who used to divide his nights between the twin tasks of gambling and producing 11 children. My father, on the other hand, had a definite puritanical streak. He was equally horrified at both these nocturnal activities, and as a result I was an only child.

For my father I was that hoped-for future generation, the generation that would fulfil his dream of staying at school, of going to university and of entering the professions - and above all of not spending a lifetime, as he had done, in the tailoring sweatshops of Leeds. I did go to medical school. I did qualify. But then my own dream of being a lifelong scholar floated me off into a privileged life, and one that his life in the sweatshops had earned for me.

My mentor at the Department of Human Anatomy in Oxford was Max Cowan. Max's background was not

*Correspondence: G Raisman, Spinal Repair Unit, Institute of Neurology, University College London, Queen Square, London WC1N 3BG, UK

An Inaugural Lecture given by Geoffrey Raisman, DM, DPhil, FRS on appointment to the Chair of Neural Regeneration and the inception of the Spinal Repair Unit at the Institute of Neurology, University College London unlike mine. He came from a struggling Johannesburg family of mining engineers. Before emigrating to South Africa, his father had been a shipyard worker in Glasgow, put out of work by the Depression. Max's parents wanted their son to be a doctor. And he failed them in just the same way as I did my father a few years later. Max's interest was the interweaving patterns of wiring of the brain. And his life and mine interwove, and for me he was a second father. On entering the world of research as Max's first DPhil student in 1960, my reward was a brand new Zeiss light microscope for my very own use. Through it I caught a glimpse of a world of orderliness and beauty. But the forms I saw resembled nothing seen in the world outside. Their meaning was hidden and mysterious. They have never lost their fascination for me, and they draw me still.

At that time the technology was developing to look at the brain with ever higher magnification. Until then, the light microscope had allowed a magnification of up to a limit of a thousand fold. Now the electron microscope took us into the millions. I was drawn, like an explorer, into an unseen world. It was a world of intense order. Once magnification reached the millions, we could see the ultimate connections between nerve cells, the synapses (Figure 1A), first described only a few years earlier. ${ }^{1}$ We had got down to the level of the individual bytes of the computer. And here the certainties that had held for centuries broke down, ideas that had seemed firm and immutable dissolved. 

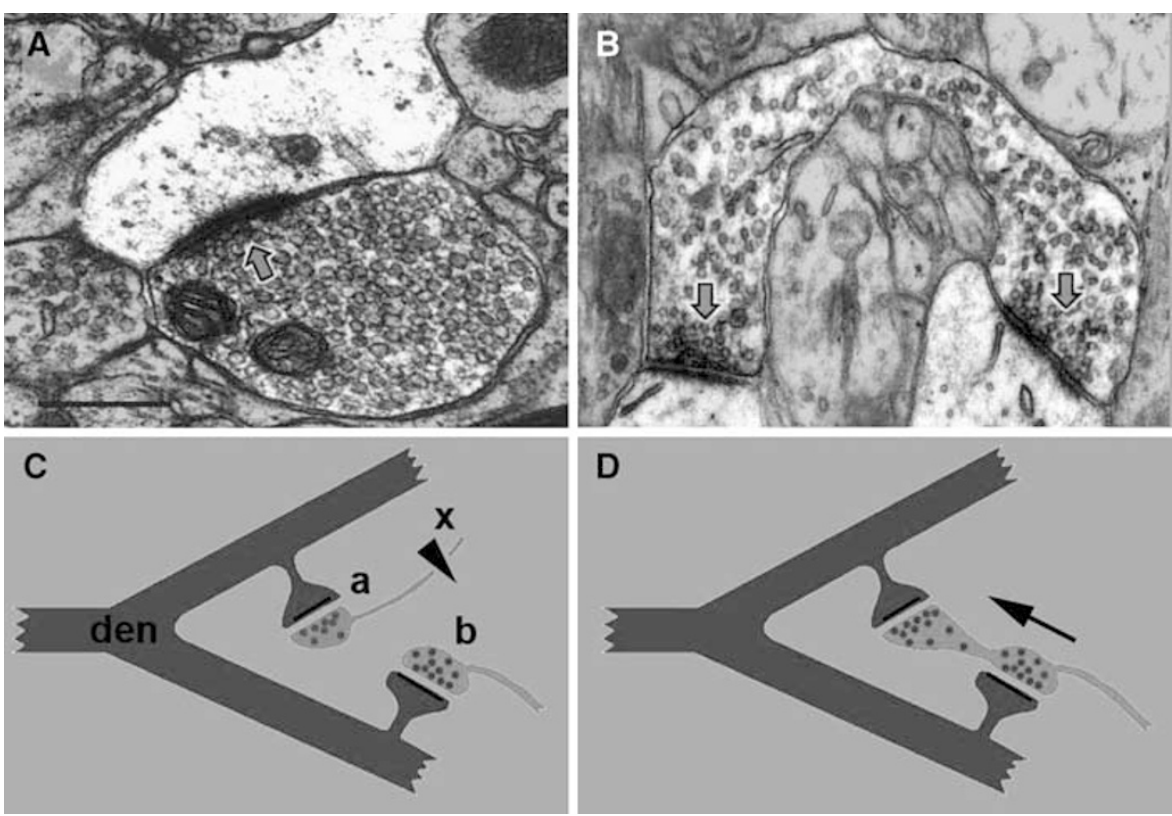

Figure 1 Plasticity. (A) Electron micrograph showing a vesicle-containing axon terminal making synaptic contact (arrow) with a postsynaptic thickening on a dendritic spine. (B) A 'double synapse' in which an elongated, horseshoe-shaped synaptic terminal makes two contacts (arrows) with separate postsynaptic thickenings on two postsynaptic elements. (C) Proposed mechanism in which the axon of origin of synapse $\mathbf{a}$ is severed (x) and an adjacent undamaged axon terminal (b) sprouts out (arrow in D) and forms an addition synaptic contact to take over the vacated postsynaptic site. Rat septal nuclei. Scale bar, $0.5 \mu \mathrm{m}$

At the staid magnification of light microscopy, the nerve cells stood as motionless as a forest of trees, silent in a windless sky. Not so at the electron microscope level. Sitting, head bowed, before a glowing green fluorescent screen in a darkened room, both arms stretched out round the shining stainless steel column of the electron microscope to reach the stage moving controls, was like snorkelling a swaying kelp forest. All was in a state of flowing motion, all was in continual change. But it took us some time to understand even a fraction of what we were seeing.

I remember one rainy afternoon when I was desperately trying to enliven a dull tutorial in anatomy. Searching for something to say, I pushed an electron microscope photograph at the student. 'What do you think that is?'

It was what I later came to call a double synapse (Figure 1B).

'Could that be the basis of memory?' I wondered aloud.

I did not realise it at the time, but my lifetime's work began at that moment. For here at last was a clue as to how the brain can change, can learn.

Of course we could not see change in electron microscope sections. But by developing specialised sampling techniques, and constructing a time based series, the changes could be inferred. And this was my first discovery, the one that was to hook me like the gambler whose first penny in the slot machine brings down a jingling jackpot of pennies, a fatal, irresistible, one-shot addiction. And that set my life's pattern.
The observation was not complicated. I was studying the effect of cutting a tract of nerve fibres called the fimbria. When the fimbria is cut $85 \%$ of the synapses in the septal nuclei degenerate. This was not surprising. Imagine the nerve cells as like those Indian gods with many arms and hands. It was as though several arms had been lopped off. Detached from their nerve cell bodies, the synapses decayed and broke down as irretrievably as would hands belonging to detached arms. What was new and surprising was that within 2 days the synapses had started to come back, and the process continued, until by 2 weeks the full normal complement was restored. But the arms had neither regrown nor reattached themselves. The detached arms were absolutely lost. What had happened was that adjacent hands belonging to intact arms had sensed the vacated space around them, and had sprouted out new hands to take it over (Figure 1C, D).

Imagine a ring of dancers holding hands. One dropped out, the ring was momentarily broken open until, in a flash, the dancers on either side joined hands around the empty space, completing the ring again.

Now this proposal cut across one of the most rigid tenets of neurology. The establishment view was that after damage to the brain or spinal cord there was no possibility of recovery. From this, it was assumed that it must also be the case that when connections are lost, no reconstruction can occur. But, just as the Albigensian heresy was spread by word of mouth from village to village in the Pyrenees, neuroanatomists and neurophysiologists at the research frontiers were already beginning to question the ancient dogma. One nest of the new 
questioners was associated with Professor JZ Young and Pat Wall at University College London. What if memory and learning involved forming new connections? ? $^{2}$ At least a partial recovery occurs after most injuries: could this be due to regeneration? What was the meaning of the observations that damage causes adjacent undamaged nerve fibres to sprout, ${ }^{3,4}$ and new pathways to be unmasked? ${ }^{5}$

Into this sea of heretical questions dropped my observation that here, in this hitherto unobserved kelp forest of the very small, new synapses were forming, not only forming rapidly, but also to a degree that efficiently replaced all the ones that had been lost. It hinted at a simple rule of nature: our brains have fixed numbers of connections, and the brain can and does restore and maintain them in the face of injury. I called this property plasticity. We are still far from understanding the mechanism that brings this about.

It was amazing, if not altogether agreeable, to find how unwilling the world was to accept a new idea, especially when it was a positive idea that challenged a previous negative one. For the first 2 or 3 years I felt quite unable to publish the evidence of plasticity. Until one day I divulged my thoughts, and my timidity, to our old and famous emeritus professor of anatomy, Sir Wilfrid LeGros Clark. He simply said, 'A person who never makes a mistake never makes a discovery.'

So I published it, ${ }^{6}$ and later further pointed up its implications in a paper entitled 'What hope for repair of the brain?'? In my mind at that time it was an entirely theoretical question, a rhetorical one. And an answer to it was something I never imagined to be within my lifetime. And, true to form, the chairman of a session at the Royal Society intervened after my presentation. ${ }^{8}$ 'Before there are any questions,' he said - and the great gold mace of the Royal Society lay on its plump red velvet cushion in front of him - 'before allowing any questions I feel it is my duty to point out how dangerous this is. What if a mother comes to me and says 'My little Willie has got brain damage, can you repair it?'

His words typify the attitude of many senior academics of that time. It was a deferential time, a cap-doffing time. Oxbridge academics considered themselves an aristocracy, superior to the mere mortals of the hoi polloi around them. Little Willie and his half-wit mother were, of course, figures of fun, cartoon cutouts from the popular press. But not being made of heroic stuff, I did not dare reply, although I have often thought over the implication of his words, in the way you think of the perfect response as you go home humiliated and seething inside, and when it is far, far too late to make it. My Parthian response would be simple: If it is dangerous to raise hopes, then medical research will have to be either (a) totally irrelevant to human suffering, or else (b) it must be carried out in secrecy.

Hope, like truth itself, cannot be qualified as false or true. Hope is hope. The man ascending the scaffold is entitled to hope, however unlikely, for the sound of hooves thundering on the cobblestones, the horse's nostrils distended, the messenger, flying, with his hot hands holding a last minute reprieve, its ink still not dried, from the king. To give hope is surely not a crime. The crime is to take it away.

Around 10 years after its first publication, towards 1979 , the fury of opposition to plasticity had all but died down. And by now it is a section in textbooks, and at meetings. And gradually, for me, the concept of plasticity has opened a window on two great vistas, one practical, and one philosophical. Both have only just begun to reveal something of their secrets. I believe they will continue to do so long after us.

The practical line of thought was Little Willie. If new synapses form automatically after injury, and if the brain, throughout adult life, maintains the same numbers of synaptic connections, then maybe it can shuffle them around, like a kaleidoscope producing, at every shake, ever-changing patterns out of a fixed number of bits of coloured paper. And, with this thought, how much more was I encouraged towards that ultimate goal, the repairing of Little Willie.

But here was a paradox. If the brain automatically restores numbers of new synapses to replace old ones, why do the brain and spinal cord not recover after injury? Why do they not repair themselves? And this problem was made even more puzzling by the observation that nerve fibres which have been severed after injury sprout vigorously.

I take the dog for its early morning walk in the park. Last autumn the poplars had been pollarded. Over the winter the cut branches produced new sprouts. They are still growing to this day. But, just as the sprouts of the felled trees never succeed in regrowing the original single trunk, so the mass of sprouts produced by cut nerve fibres fail to advance to their original destinations. And so they cannot restore their original connections. The question was: how can they be made to do so?

The first Ariadne thread that led through this labyrinth of puzzles was provided by the great father of neuroanatomy, the Spaniard Santiago Ramón y Cajal, hero of Aragon, working in the nineteenth century. Cajal was struck by the fact that nerve fibres in the peripheral nervous system, the nerves of the body and limbs, readily and rapidly grow for long distances when severed. He proposed that transplantation of a piece of peripheral nerve into the damaged brain would encourage the growth of the severed nerve fibres. ${ }^{9}$

Cajal's proposal was shown to be correct, both by transplantation of pieces of peripheral nerve, ${ }^{10}$ and by transplantation of Schwann cells cultured from peripheral nerve. ${ }^{11}$ But unfortunately the regrowing nerve fibres, while entering the graft, would not leave it. As a result they could not get back to their original targets and thus were unable to restore their lost connections and functions. The key to the problem of reconnection was still elusive. We had the hieroglyphs, but, unlike Champollion, we as yet had no Rosetta stone to decipher them.

The conundrum posed by these observations on transplantation of peripheral tissue led me to a further thought: What if the nerve fibres were not at fault? What 
if the problem was in the pathway? The pathway along which nerve fibres travel consists of glial cells. We have immense numbers of nerve cells in our brains, but their number is exceeded in orders of magnitude by the glial cells. This is true for all brains, but the preponderance of glial cells increases proportionately more as we go up the evolutionary sequence leading to the largest brain of all, the human brain. In primates the ratio of glial cells to neurons is greater than in other mammals, and it is greatest of all in humans. And plasticity of function is greatest in the human brain. Could it be that the glial cells play the crucial role in plasticity? ${ }^{12,13}$ What if the cause of the failure of regeneration of severed nerve fibres lay not in the nerve cells but in the glial cells of the pathway?

Imagine the nerve cells to be cars travelling along a motorway. Storm clouds break over the Pennines. Torrential rain floods down the hillsides, the River Trent rises and washes away a stretch of the M1 in Nottinghamshire. The drivers of the cars coming south from Edinburgh still remember where they were going. The drivers of the cars heading north from London still remember where they were going. The places they were going to still await their arrival. The drivers' dinners are still waiting on the table. The cars buzz around. The drivers fume and fret and rev up angrily. But it is of no value to change the traffic lights from green to red. No value to give them more petrol. The cause of the problem lies neither in the cars nor the drivers. What is needed is to repair the roadway (Figure 2).

I call this the pathway hypothesis. And I propose that, until proved otherwise, we may at least test the assumption that repairing the roadway is both necessary and also sufficient for repair. It is enough for correct regrowth of the nerve fibres, and it is enough for functional recovery. No traffic lights need be adjusted, no petrol tankers need to be rushed to the scene, no dying drivers need to be rescued or resuscitated.

But so far, this is a hypothesis, a flight of imagination, engaging maybe, but not a fact. So how to prove it? Where can we find those magic cells, that road gang of navvies who will repair the pathway? Cajal's proposal had shown that transplants of pathway cells from limb nerves had a value, but only a limited value. Cajal's idea had been to transplant pathway cells from a part of the body - the peripheral nerves - where nerve fibres can

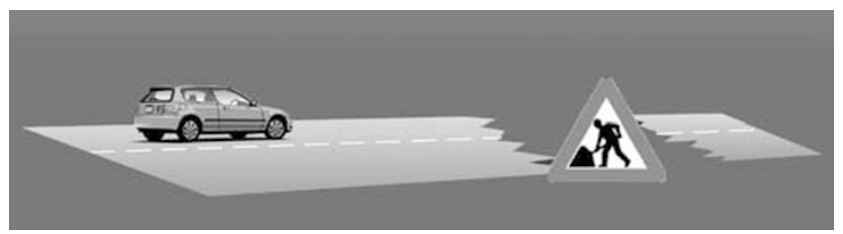

Figure 2 The pathway hypothesis. The nerve fibres are represented by the car, the astrocytic pathway by the roadway. The nerve fibres retain an intrinsic ability to grow, and their original targets remain able to accept terminal synaptic contacts by the regenerating fibres. What is required for repair is that the pathway is re-established by repair of the roadway grow, into a part of the body - the brain and spinal cord - where they cannot grow. Is there a source from which we might obtain better pathway cells?

The first clues came from studies of the development of nerve fibres in the embryo. During the development of the embryo, the nerve fibres of the brain and spinal cord are able to grow. Studies of how nerve fibres grow during embryonic development showed that the nerve fibres advance along primitive pathway cells, which are called radial glia. ${ }^{14}$ After birth, the radial glia mature into adult pathway cells, or astrocytes, which change their orientation and become aligned like railway tracks and provide the structures along which adult nerve fibres travel. But, unlike their growth-permissive radial glial precursors, after an injury in the adult the astrocytic environment of the adult brain and spinal cord no longer permit the regrowth of severed nerve fibres.

It has often puzzled observers that the ability to regenerate pathways in the brain and spinal cord is present in cold blooded vertebrates, but is lost at the evolutionary point leading to mammals. What could be the adaptive value of apparently discarding such an obvious advantage? I propose that this is associated with the assumption of a dual function by adult astrocytes, that apart from their role in providing aligned structures for the passage of nerve fibres, the adult astrocytes have quite another function, a vital protective one.

Adult astrocytes are essentially asymmetrical cells. They have an 'inner' surface facing nerve fibres, and which I propose is permissive to nerve fibre growth, and an 'outer,' non-permissive surface lined by basal lamina and facing either the blood vessels (where they maintain the blood brain barrier, ${ }^{15}$ or the pial surface, where they form the exterior wall of the central nervous system (Figure 3A). Astrocytes respond within hours of any injury, and they do so by rapidly sealing off the injury site (Figure 3B). This is an essential protective reaction, needed to reseal the breach that the injury makes into the privileged environment of the central nervous system. The resealing is needed to maintain the special ionic balance essential for the functioning of the brain and spinal cord, and to exclude damaging intrusions. The mass of sealing off astrocytes is called the astrocytic scar. But in forming the scar, the astrocytes abrogate the aligned glial pathway or permissive surfaces which the sprouts of the severed nerve fibres need for elongation. What is needed is to reorganise the astrocytes so as to open up the scar, and persuade them to remake an aligned pathway (Figure 3C). But how can we reintroduce the embryonic property for permitting growth into an adult system which has lost it? How can we perform a transplant not only in space, but in time?

Just before leaving Oxford, I had the privilege of playing host to a visit by the great neuroanatomist JZ Young, of University College London. JZ's lifelong interest in the neural mechanism of memory made him receptive to any suggestion of plasticity at the anatomical level. At that time there was great interest in a newly developed technique for identifying the birthdays of 


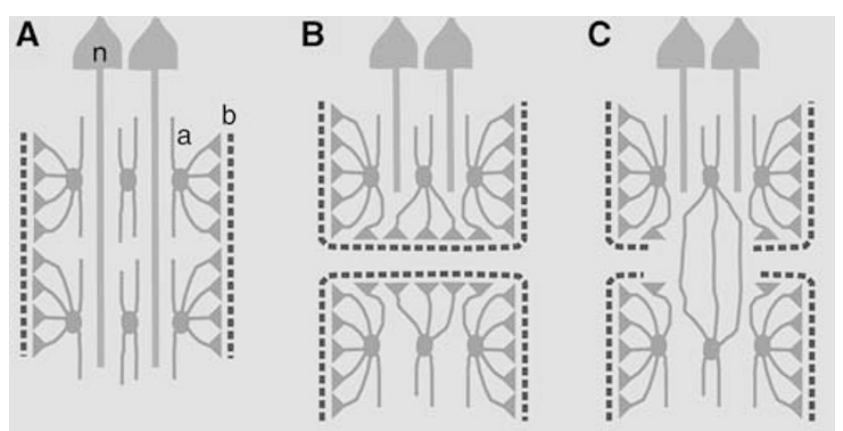

Figure 3 Repair of the astrocytic pathway. (A) Astrocytes (a) form an elongated aligned pathway for nerve fibres (n) but also generate end feet lined by basal lamina (b; broken lines), which form the pial surface of the brain and spinal cord. (B) After an injury the astrocytes rapidly reorganise themselves to form a complete barrier of basal-lamina lined end feet which reseal the pial surface over the injury, but at the same time abrogate the aligned pathways needed for advance of the regenerating nerve fibres. (C) The requirement for regeneration is that the astrocytes reorganise themselves so as to reestablish longitudinal pathways to permit the advance of the nerve fibres

nerve cells by using an autoradiographic labelling technique based on the incorporation of radioactive tritium into the nuclear DNA of newly dividing cells. ${ }^{16}$ I explained it to JZ; he listened gravely. Encouraged by his interest, I became increasingly bold and enthusiastic, until finally, I said, 'With this new technique, the sky's the limit.' 'Geoffrey,' he said, softly, 'it is indeed an exciting method. But I would be careful of the sky.'

Some years later, while pondering where I might find the transplant which could repair the pathway and enable the severed nerve fibres to grow back to their original destinations, it turned out that a possible answer was already at hand. Unnoticed by anyone, it came from they very technique about which I had so enthused to JZ.

Until that time it had been assumed that we are born with a fixed number of nerve cells, and the best that we can do is to try to prevent losing them to alcohol, or to boxing, or to Alzheimer's or Parkinson's diseases. That is still very largely how we understand things. But in the 1960s, Pasquale Graziadei, a former student of JZ at University College London, was working in Florida. He had shown that in one part of the nervous system - and so far in the only one that we know of - nerve cells are continually replaced throughout adult life. ${ }^{17}$ This is the olfactory system, the part of the nervous system lying in the upper nasal lining and carrying the sense of smell. And this process of continual renewal reflected the persistence of an embryonic property, the property of cell division. So here, in the adult, was a fount of unending youth. And maybe a source of pathway cells? But that's hindsight. We're racing ahead. The idea of transplanting pathway cells from the olfactory system took quite a bit longer, quarter of a century to be precise.

The fibres arising from the newly formed olfactory neurons pass through the skull and terminate in the olfactory bulbs. Moreover, Graziadei et al ${ }^{18}$ had shown that if an olfactory bulb was removed, the olfactory nerve fibres would continue to grow through the cranial cavity until they reached the next area, the frontal cortex, which they then entered and made connections there. So the olfactory nerve fibres have the property of entering parts of the brain which do not normally receive them. But how do they do it?

Graziadei's observation passed practically unnoticed. It was only some 10 years later, and after his untimely death, that the significance of his work began to percolate into my consciousness. Based on the pathway hypothesis, I had speculated that the ability to grow depended not on the nerve fibres, but on the presence of specialised pathway cells. Finally, in $1985,{ }^{19}$ I first described a type of pathway cell, unique in structure and arrangement, and found only in the primary olfactory pathway. This cell is now called the olfactory ensheathing cell. ${ }^{20}$

Some years later Doucette in Canada described how to obtain olfactory ensheathing cells in tissue culture of samples taken from the adult olfactory system. ${ }^{21}$ And with this knowledge the stage was set for us to begin to transplant them. In doing this, we were carrying out a transplant not only in space, but - so to speak - in time, from a part of the body which retains embryonic characteristics into a part of the body which has lost them.

The results were beyond our dreams. ${ }^{22}$ The cells survived transplantation, and they opened up a pathway (Figure 4), which allowed the growth of severed nerve fibres. The transplanted cells formed a bridge conveying the regenerating nerve fibres across the injury (Figure 5). They had repaired the roadway. A bridge had been thrown across the washed out motorway and the cars were driving across it. But most important - they restored function (Figure 6).

I will never forget one early morning, sometime in the dead period between Christmas and New Year, when for some reason I decided to examine the rats at about 0200 hours. On the way to the animal house I remember my breath coming out as steam in the frozen night air. The test was for the rat to retrieve a piece of food I offered it. It was a rat which had a unilateral lesion of the left corticospinal tract at the upper cervical level. Since the time of lesioning, it had never used its left paw for retrieval. The damage was on the left, and the cultured olfactory ensheathing cells had been transplanted into the lesion.

Then I could hardly believe my eyes. The rat put its left paw forward, just tentatively then paused. I was amazed. But I think the rat was equally amazed. For a moment we looked at each other in surprise. Then it went on and took the food. And at that moment I knew the breakthrough had come. It was a moment that occurs once in a lifetime - if you are lucky. Many years followed. Repeat, extend, confirm. We examined three systems in the rat. First the animals recovered the ability to retrieve pieces of food with the forepaw of the operated side. Second they learned to recover the use of 

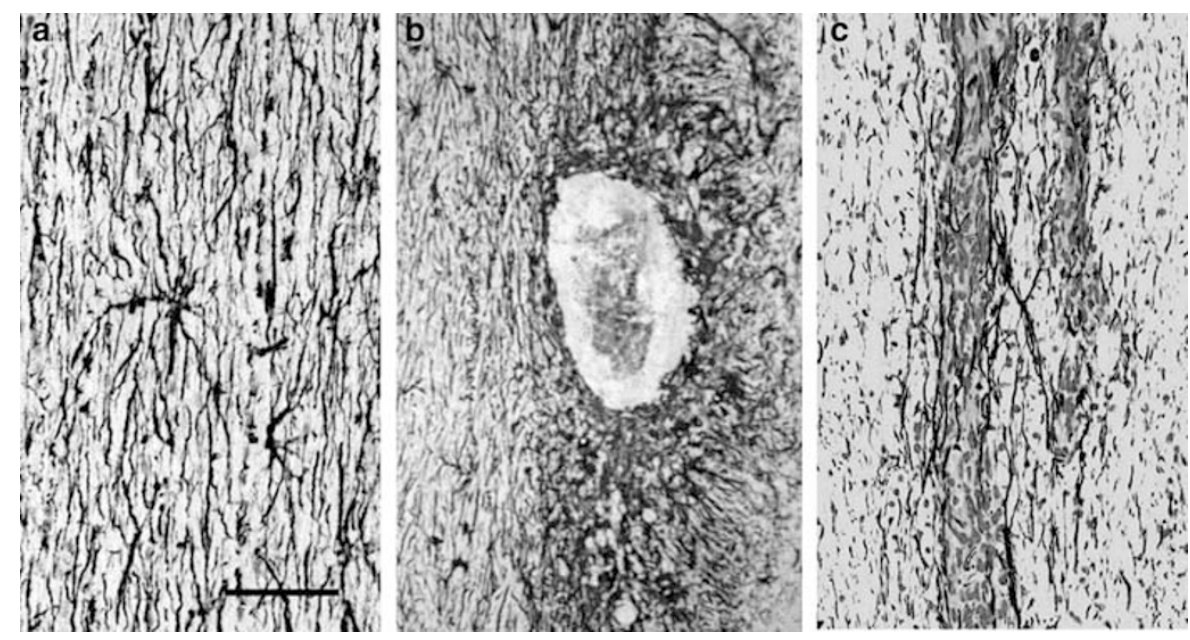

Figure 4 Repair of the astrocytic pathway by transplantation of olfactory ensheathing cells into a lesion of the rat corticospinal tract. (a) The normal longitudinally aligned parallel array of astrocytic processes in the corticospinal tract. (b) Dense astrocytic scar formed around an electrolytic lesion. (c) Reorganisation of the astrocytic processes to form a newly aligned pathway across a lesion into which olfactory ensheathing cells have been transplanted. Scale bar, $50 \mu \mathrm{m}$

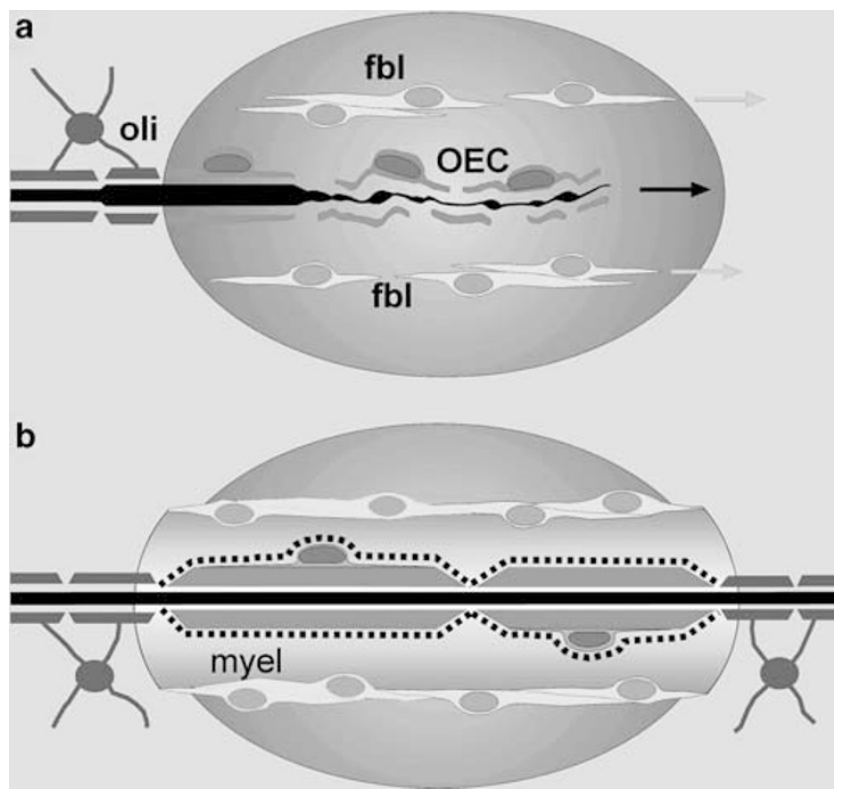

Figure 5 Regrowth of nerve fibres across a lesion of the rat corticospinal tract transplanted with olfactory ensheathing cells. Reparative effect of olfactory ensheathing cells (OEC) and their associated olfactory nerve fibroblasts (fbl) on severed corticospinal axons. (a) During the first week, the axons advance, intimately surrounded by OECs and flanked by advancing fibroblasts. (b) During the third and fourth weeks, the axons have proceeded through the transplant, where they are now myelinated (myel) by OECs, thus forming a bridge from the oligodendrocytic myelin territory (oli) at the cut, proximal end all the way through the transplant to re-enter the oligodendrocytic territory at the distal end. Modified from $\mathrm{Li}$ et $a l^{23}$

the paw for climbing. And third the transplants restored the breathing ability to the diaphragm of the operated side. $^{24}$

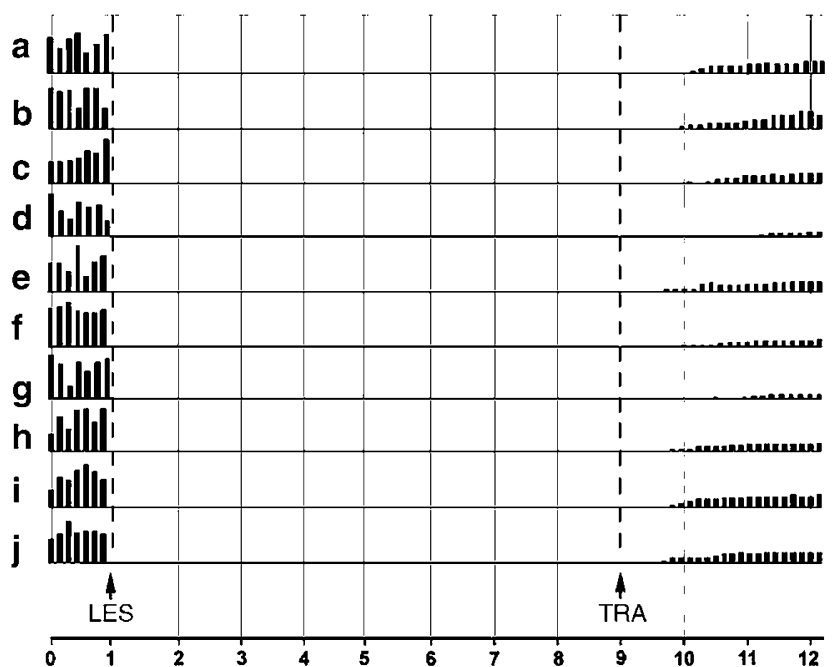

Figure 6 Restoration of paw reaching by olfactory ensheathing cells transplanted into functionally complete unilateral lesions (LES) of the upper cervical corticospinal tract in the rat. Ten rats $(\mathbf{a}-\mathbf{j})$ with complete absence of paw reaching (ordinate) on the operated side for 8 weeks after transplantation (abscissa in weeks) all showed spontaneous return of function at 5-10 days after transplantation (TRA) of olfactory ensheathing cells

The ability to engineer the re-entry of nerve fibres into the spinal cord is a proof of principle, or rather of principles. These principles are:

(1) There exist, in all of our bodies, adult stem cells which can be used to generate reparative tissues. No need to resort to embryonic cells. No need to cross any immune barriers or use any immunosuppressive drugs. The patient can be his or her own donor. 
(2) Severed nerve fibres can be reconnected in an adult spinal cord.

(3) Lost functions can be restored.

In 1974, I moved from the Department of Human Anatomy in Oxford to the National Institute for Medical Research at Mill Hill, where the Medical Research Council supported my research work for many years. This gave me the opportunity to work out the basic methods for transplantation of cultured olfactory ensheathing cells, and to study the reconnection and functional repair in rats. But still I was far from having these dreams applied. It was only in 2005, with the move of the research team to the Institute of Neurology in Queen Square, that we finally had access to the neurosurgeons who were both willing and also had the opportunity to plan for the clinical application of olfactory ensheathing cell transplants.

We already have permission for the first preliminary safety study, which is scheduled for this year, 2006. Our first attempt will be to repair avulsed dorsal roots. ${ }^{25}$ Success would open the way to evolve techniques for repairing larger ('transverse') spinal cord injuries, as well as brain injuries resulting from some of the most severe types of stroke, those affecting descending motor pathways, and blindness and deafness caused by damage to the fibres of the nerves of vision and hearing.

I hope our team can contribute to some of these. But we need to be realistic. We have not learned how to repair a twelve-lane metalled motorway. If we are lucky we will be able to throw a plank over where a stream crosses a field path. We have not yet invented tarmacadam or reinforced concrete. We do not know how to build cantilevered bridges. There will be many more developments needed for the motorway engineers of the future.

But after all, in the end our success is not that we have done this, but that we have opened a door through a wall that was impenetrable. And repair of injuries is only one aspect of the concept of plasticity. Evolution did not develop plasticity as a potential method for repairing injuries, a method which would lie unachieved and dormant for millions of years until someone thought of transplanting olfactory ensheathing cells. For me, the concept of plasticity opened a much wider significance.

After all, what is the function of the brain? It is not claws and teeth but the brain that is the principal organ of evolution. The battle is to the wily, not to the strong. If we ask what is the function of the brain, the usual answers may be to move the hands, to see, to hear. But these are pretty lowly, mechanical functions, something a robot with a computer might imitate. But look around! Everything we see around us is a creation of the human brain. Nothing is of nature. We made or modified it all, even the sky itself bends to our wills however blind to the consequences. That is the important function of the brain. And it was not the brain of an individual, or of one time, but of an organised society of brains, acting over a long period.
The function of the brain is plasticity, the ability to change, not to respond the same way twice. If it's good, go for more. If it's bad avoid it. Explore, be curious, remember, learn, build, form concepts. And pass them on to future generations. Those are the important functions of the human brain. Those defined our brains. And all of them involve plasticity. The ultimate expression of plasticity is history itself, the ever changing.

This is meant to be an inaugural lecture, but I wonder what I am inaugurating. So large a part for me personally is a valedictory. But all our activities in the end are only an inauguration of what will follow. Research, knowledge, do not belong to anyone. Like the earth itself, they belong to no one. Rather we belong to them. And human evolution is social evolution. The advances come not from a person, but from a team. It is a joy for me to see ideas floated out among our little team, like rose petals in a whirlpool, finally forming a pattern that no single one of us alone could have framed. And so this article uses the word ' $I$ ' where it means 'we.' If I pick out Ying $\mathrm{Li}$ and Daqing $\mathrm{Li}$, who have given 20 years to this project, and who have changed their homeland to do it, it is not to detract from the many contributors and supporters along the way, who are too numerous and too varied to acknowledge.

This article is not intended to be a review of the wider field of neural regeneration (of which there are many available ${ }^{26}$ ), nor to document the work on repair by transplantation of cells. Its purpose is only to record, with the inevitable distortions, omissions, and creations of fallible memory, some of the glimpses of the mysterious countryside seen from the rather cloudy windows of a fast moving train, a personal journey.

\section{Acknowledgements}

Principal funders have been Norman and Sadie Lee Foundation, the Medical Research Council, the British Neurological Research Trust, Spinal Research, the Charity of Henry Smith, and the Barnwood House Trust.

\section{References}

1 Palay SL, Palade GE. The fine structure of neurons. J Biophys Biochem Cytol 1955; 1: 69.

2 Young JZ. The organization of a memory system. Proc Roy Soc Lond B Biol Sci 1965; 163: 285-320.

3 Liu CN, Chambers WW. Intraspinal sprouting of dorsal root axons. Arch Neurol (Chic) 1958; 79: 46-61.

4 Goodman DC, Horel JA. Sprouting of optic tract projections in the brain stem of the rat. J Comp Neurol 1966; 127: 71-88.

5 Wall PD, Egger MD. Formation of new connexions in adult rat brains after partial deafferentation. Nature 1971; 232: 542-545.

6 Raisman G. Neuronal plasticity in the septal nuclei of the adult rat. Brain Res 1969; 14: 25-48.

7 Raisman G. What hope for repair of the brain? Ann Neurol 1978; 3: 101-106. 
8 Raisman G. Formation of synapses in the adult rat after injury: similarities and differences between a peripheral and a central nervous site. Philos Trans Roy Soc Lond (Biol) 1977; 278: 349-359.

9 Cajal SR. Degeneration and Regeneration of the Nervous System. Hafner: New York 1928.

10 Vidal-Sanz M, Bray GM, Villegas-Pérez MP, Thanos S, Aguayo AJ. Axonal regeneration and synapse formation in the superior colliculus by retinal ganglion cells in the adult rat. J Neurosci 1987; 7: 2894-2909.

11 Paíno CL, Bunge MB. Induction of axon growth into Schwann cell implants into lesioned adult rat spinal cord. Exp Neurol 1991; 114: 254-257.

12 Field PM, Raisman G. Relative slowness of heterotypic synaptogenesis in the septal nuclei. Brain Res 1983; 272: 83-99.

13 Allen NJ, Barres BA. Signaling between glia and neurons: focus on synaptic plasticity. Curr Opin Neurobiol 2005; 15: 542-548.

14 Easter Jr SS, Ross LS, Frankfurter A. Initial tract formation in the mouse brain. J Neurosci 1993; 13: 285-299.

15 Janzer RC, Raff MC. Astrocytes induce blood-brain barrier properties in endothelial cells. Nature 1987; 325: 253-257.

16 Altman J. Autoradiographic and histological studies of postnatal neurogenesis. IV. Cell proliferation and migration in the anterior fore-brain, with special reference to persisting neurogenesis in the olfactory bulb. J Comp Neurol 1969; 137: 433-458.

17 Graziadei PPC, Levine RR, Montigraziadei GA. Plasticity of connections of the olfactory sensory neuron: regeneration into the forebrain following bulbectomy in the neonatal mouse. Neuroscience 1979; 4: 713-727.
18 Graziadei PPC, Montigraziadei GA. Neurogenesis and neuron regeneration in the olfactory system of mammals. I. Morphological aspects of differentiation and structural organization of the olfactory sensory neurons. J Neurocytol 1979; 8: 1-18.

19 Raisman G. Specialized neuroglial arrangement may explain the capacity of vomeronasal axons to reinnervate central neurons. Neuroscience 1985; 14: 237-254.

20 Ramón-Cueto A, Valverde F. Olfactory bulb ensheathing glia: a unique cell type with axonal growth-promoting properties. Glia 1995; 14: 163-173.

21 Doucette R, Devon R. Media that support the growth and differentiation of oligodendrocytes do not induce olfactory ensheathing cells to express a myelinating phenotype. Glia 1994; 10: 296-310.

$22 \mathrm{Li} \mathrm{Y}$, Field PM, Raisman G. Repair of adult rat corticospinal tract by transplants of olfactory ensheathing cells. Science 1997; 277: 2000-2002.

23 Li Y, Field PM, Raisman G. Regeneration of adult rat corticospinal axons induced by transplanted olfactory ensheathing cells. J Neurosci 1998; 18: 10514-10524.

$24 \mathrm{Li} \mathrm{Y,} \mathrm{Decherchi} \mathrm{P,} \mathrm{Raisman} \mathrm{G.} \mathrm{Transplantation} \mathrm{of}$ olfactory ensheathing cells into spinal cord lesions restores breathing and climbing. J Neurosci 2003; 23: 727-731.

25 Li Y, Carlstedt T, Berthold C-H, Raisman G. Interaction of transplanted olfactory-ensheathing cells and host astrocytic processes provides a bridge for axons to regenerate across the dorsal root entry zone. Exp Neurol 2004; 188: 300-308.

26 Fawcett JW, Rosser AE, Dunnett SB. Brain Damage, Brain Repair. Oxford University Press: Oxford 2001. 